\title{
Analysis of the Problems, Causes and Countermeasures in the Brand Construction of the Postgraduate Entrance Examination Institutions
}

\author{
Yuanle Cheng, Hai Hu \\ Business School, Nanjing Normal University, Nanjing, China \\ Email: 2371797839@qq.com
}

How to cite this paper: Cheng, Y.L. and $\mathrm{Hu}, \mathrm{H}$. (2020) Analysis of the Problems, Causes and Countermeasures in the Brand Construction of the Postgraduate Entrance Examination Institutions. Open Journal of Business and Management, 8, 396-413. https://doi.org/10.4236/ojbm.2020.82025

Received: December 23, 2019

Accepted: January 13, 2020

Published: January 16, 2020

Copyright $\odot 2020$ by author(s) and Scientific Research Publishing Inc. This work is licensed under the Creative Commons Attribution International License (CC BY 4.0).

http://creativecommons.org/licenses/by/4.0/ (c) (i) Open Access

\begin{abstract}
In the theory of brand life cycle, there are three stages of brand: entry, growth, maturity and decline. In the initial stage of establishing a brand, the postgraduate entrance examination institution paid a huge cost of human and material resources. When the brand has a little popularity, there is little investment in continuing to expand the popularity, and there is a lack of continuous investment. At present, the brand of the postgraduate entrance examination institution is in the growing period. Maintaining the brand popularity, making it not decline, even more brilliant needs to carry on the brand operation. Brand marketing needs both internal and external innovation of the brand [1], combining the four elements of marketing products, prices, channels and services, and achieving brand maintenance through advertising monitoring, word-of-mouth marketing, user management and other ways. Promote the brand image, increase the brand awareness, and realize the continuous brilliance of the brand. This paper analyzes the problems and causes in the brand construction of postgraduate entrance examination, and puts forward corresponding solutions. This paper analyzes the problems and causes in the process of building the brand, and finds out the rules and ways to build and maintain the brand of education and training institutions.
\end{abstract}

\section{Keywords}

Brand Life Cycle, Brand Building, Brand Innovation, Service Quality, Marketing

\section{Introduction}

With the development of social economy, enterprises pay more and more atten- 
tion to the quality and education of employees. More and more college students choose postgraduate entrance examination. The tutoring market for postgraduate entrance examination is booming, and the tuition fees for individual students vary from 2000 - 100,000 yuan, with huge profits. The number of tutoring institutions for postgraduate entrance examination is increasing rapidly, and there are more than 10 institutions for postgraduate entrance examination in a university. The competition among various organizations is fierce, and the establishment of enterprise brand can form a huge advantage, and the strong enterprise brand is bound to occupy a larger market share in the market. The purpose of this paper is to explore the problems in the establishment and maintenance of the brand of the postgraduate entrance examination institutions, and to explore and summarize the successful experience of the growth of the postgraduate entrance examination education brand.

The thesis on market analysis and brand building of educational institutions is summarized as follows:

The first stage: since the birth of the postgraduate education industry more than 20 years ago, it has gradually formed a hot situation of postgraduate entrance examination and a large number of postgraduate entrance examination guidance classes. Then there are a series of problems: illegal operation, false propaganda, advocacy of super teachers, topic rate, teaching aids and so on. There are many kinds of advertisements, promises not fulfilled, face-to-face teaching into video courses, etc. The establishment conditions of the institution are not clearly defined, the operation mechanism is not regulated by law, the supervision is not effective, the quality of the practitioners is low, and the college students are lack of awareness and rights protection ways, etc.

The second stage: the state began to attach importance to the postgraduate education industry, and treat education and training institutions as companies. In this regard, the State formulates relevant laws, strictly regulates the nature of the postgraduate entrance examination training industry, establishes strict regulatory measures, requires regular vocational training for employees, standardizes the form and content of advertisements, etc.; from the perspective of colleges and universities, strengthens the popularization of postgraduate entrance examination knowledge and education for students, plus the correct guidance of public opinion.

The third stage: when the postgraduate education industry gradually standardized, the postgraduate education institutions began to pay attention to the construction of education brand. All major educational institutions have begun to invest in teachers, courses, materials, services, technology, management, marketing and other aspects in an attempt to improve their visibility in the market and gain more market share.

The fourth stage: scallop brand life cycle means that the brand life cycle line like scallop extends and extends continuously, which is in the mature period for a long time and keeps healthy growth for a long time. At present, most of the domestic well-known education and training institutions have entered the 
growth stage and mature stage, and are in the key period of whether they can maintain long-term stable growth and go well in the scallop life cycle. Brand maintenance management is required.

\section{Theoretical Review}

The theory of brand building in foreign studies was first put forward by Manfrey Brunen, and the brand has three stages: entry stage, growth stage, maturity stage and decline stage; later, John Philip Jones put forward the theory of scallop life cycle, and the brand has three stages: incubation, initial growth and recycling stage.

In the domestic research, Meijiawu put forward the concept of brand building in the article on brand building: brand is a symbol to replace products, which can transmit the symbol information different from other products to consumers, facilitate consumers to identify and form a kind of recognition in consciousness [2]. Brand building is essential for an enterprise. Brand can make the enterprise operate more standardized, leave a deeper impression on consumers, improve the popularity of products, and then improve the market share.

Brand building is divided into three stages: concept stage, concept stage and culture stage. In the concept stage, enterprises are required to design distinctive brand symbols, choose eye-catching publicity positions, and effective communication channels to attract consumers' attention as much as possible to let more people know the brand. In the concept stage, people pay more attention to let people know the connotation of the enterprise, from the appearance of the brand to the essence of the brand, which makes people associate with each other. Through the brand name, people can quickly think of all aspects of the enterprise's products, and let consumers know what they can't know through the brand logo. In the cultural stage, the corporate culture is promoted to the level of spreading corporate culture. By fulfilling the social economic responsibility, cultural responsibility, political responsibility and educational responsibility, the corporate brand is spread among the public, so as to achieve a win-win situation between the enterprise and the society.

In 2013, Chen Yan studied the main problems existing in the brand maintenance and management of education and training institutions in the life cycle in the article "maintenance and development of education and training brand based on the concept of life cycle [3]". When the brand is in the growing and mature period, brand maintenance needs to start from two aspects: the promotion of brand connotation and the operation of brand extension. Brand connotation refers to the elements of internal operation control of the enterprise. Brand extension is to pass on the things that the enterprise needs to show to consumers through some channels.

The solution to the problem in brand maintenance management is to innovate continuously. In 2014, Ge Xiaofei [4] "on the problems and development strategies in enterprise brand building" in the study of enterprise brand building, he 
thought that the main problems in the current brand building of education and training institutions are brand awareness is weak, enterprises do not pay attention to brand image, and there is no clear position on brand positioning; the means of brand building is not novel enough, blind advertising, resulting in large costs A situation in which costs and benefits are small. In view of these problems, she believes that enterprise brand building needs to be positioned accurately, adopt integrated marketing communication strategy for brand operation, and strengthen product quality and service level.

To sum up, enterprise brand building is a gradual process, from small brand to big brand, from internal elements to external image. Manfrey Bruin and John Philip Jones have come to the conclusion that brand and product have the same life cycle. The difference between them is that the former thinks that an enterprise brand will eventually die, and the latter thinks that enterprise brand can enter the cycle stage through certain measures. Meijiawu, a domestic scholar, has studied three stages of brand building, and the relevant theories of how to build a brand in each stage. Chen Yan and Ge Xiaofei, on the basis of predecessors, based on the life cycle theory, have studied the existing problems in the brand building of enterprises at this stage, and given some solutions.

At present, the research has solved the development law and several stages of the enterprise brand. The disadvantage is how to keep the enterprise brand in a good stage, not decline and not perish, and continue to bring the maximum profit for the enterprise, that is, the solution of brand maintenance and development. In my opinion, the enterprise brand can enter the cycle stage. As long as the enterprise brand construction keeps pace with the times, keeps innovating, analyzes and forecasts the future and keeps up with the general trend of social development, the enterprise brand will be sustainable. Today's development is changing with each passing day. The past brand building theory should be combined with the scientific and technological means in the new era, and brand building should be carried out through new channels.

\section{Research Methods and Findings}

In this paper, through a questionnaire survey of 30 employees and 600 college students in Nanjing Branch, and one-to-one interview with department leaders, the author makes a questionnaire survey and interview on teachers, courses, materials, services, technology, management, marketing and other aspects of the Institute, and finds out the role of all aspects in the process of brand building by using the method of data survey and statistics Collect and analyze the collected data, and get the results.

The results show that the market share of Nanjing branch is declining. For example, with the popularity of New Oriental Education Group, after entering the field of postgraduate entrance examination, Houjun raised rapidly, gaining the trust of college students, and then occupying more market share; a few other postgraduate entrance examination institutions carried out financing, increased 
market manpower, publicity cost investment, and rapidly increased the strength of competitors, resulting in the market share of other postgraduate entrance examination institutions declining.

According to the questionnaire on the recognition of enterprise advantages of the employees of the research institutes, the teachers in some of the research institutes are at a high level, with famous teachers accounting for nearly $30 \%$ of all the teachers, and non-famous teachers are also teachers who have many years of teaching experience; the research and development of curriculum system and data test paper are also a big advantage, with more than a dozen discipline research institutes, and the research and learning system of university students is not good to perfect.

But college students have experienced the long-term low-efficiency advertising bombardment of postgraduate entrance examination institutions, and gradually become tired of these things, as well as memory fatigue. They only think that these promotions are useless advertisements. They don't have a deep understanding of an organization and its products. They don't know teachers, prices, research and development, popularity and so on. The information is seriously asymmetric. Later, they just start to understand again when necessary.

\section{Analysis of Problems in Brand Building of Postgraduate Entrance Examination}

\subsection{Market Share of Some Postgraduate Entrance Examination Institutions Decreased}

Generally, the sales volume of a brand reflects the market share of the brand. The higher the market share, the greater the corresponding sales volume. Previous studies have proved that brand reputation and popularity have a positive correlation with market share. But now the market share of some institutions has declined, and there are some problems in brand maintenance management:

First, insufficient investment in brand management and maintenance. After the brand enters the growth period, the whole enterprise enters the good operation period, has certain economic strength and scale, the brand establishment enters the rough mode, does not intensive cultivation, causes the brand development to lag.

Second, the quality of products has declined. Some education and training institutions are in a state of no one's attention even after students pay their fees, which leads to confusion in organization and management, neglecting to provide thoughtful and meticulous services to students, leading to unsatisfactory results of postgraduate entrance examination and ultimately affecting the reputation of the institutions.

\subsection{Decline of Brand Awareness and Obstruction of Communication Influence}

Brand awareness refers to the ability of potential buyers to recognize or remem- 
ber that a brand is a kind of product [5], and brand awareness is an important part of brand building. The establishment of brand awareness should carry out brand communication, so that people can gradually understand a brand from life to recognize a brand, so that the popularity can be gradually established. Brand communication is that a consumer starts from contacting the brand, and the customer constantly searches for the product information, finds its unique advantages compared with the existing product brand, strengthens the cognition continuously, and finally generates and maintains the trust to the product. Brand communication is a way of practice, through advertising, public relations, interpersonal communication, news reports, service sales and products and other means of communication, and ultimately improves the brand image of everyone's cognition [6].

The marketing promotion methods of the postgraduate entrance examination institutions are old-fashioned. Now, the publicity methods used include holding postgraduate entrance examination lectures at the beginning of the school season, inviting well-known teachers to attend classes, posting posters on the campus of colleges and universities, sponsoring students to organize activities through the cooperation of schools and enterprises, and letting students carry out advertising and publicity by naming.

The purpose of these publicity is to let students sign up for the training course, and they don't pay attention to whether these publicity helps to improve the brand awareness; only the name and fragmented course information of the postgraduate entrance examination institution are passed to everyone, and the information receiver can't know how the brand value of the postgraduate examination institution is; there is no in-depth interaction between the postgraduate entrance examination institution and the customer, and the brand communication is not implemented. Brand name can be publicized by a large number of advertisements, but customers have low recognition of the brand, little understanding of the reputation and value of the brand, and do not form a profound brand image in their mind.

\subsection{The Internal Value Advantages of Postgraduate Entrance Examination Institutions Are Not Well Known by Customers}

In the initial stage of the brand, the brand usually has established its own core advantages and brand characteristics, and the brand connotation of teachers, curriculum system, teaching point hardware and software facilities has been established. However, due to various reasons, the brand has not been strongly publicized, and the enterprise has not accurately transmitted these information to consumers, so consumers do not have a high awareness of the enterprise. The postgraduate entrance examination training service is a special service business, generally there is no secondary purchase, so the well-known brand of postgraduate entrance examination is well known by the people who have completed the postgraduate entrance examination, but the people who have completed the postgraduate entrance examination and the customers of the postgraduate en- 
trance examination training class are derailed. After the completion of the postgraduate entrance examination, college students will choose to find jobs or be busy with graduation design. As for whether the postgraduate entrance examination is successful or not, which institution has successfully applied for the postgraduate entrance examination, it is difficult to transfer these information to the new customer group. Therefore, even with high service quality, after the end of old customer service, all previous marketing efforts tend to be zero effect, not known by new customers.

\section{An Analysis of the Causes of the Problems in the Brand Building of the Postgraduate Entrance Examination Institutions}

After the establishment of the Institute's brand, it is not able to maintain the brand, it has less investment in brand expansion and innovation, and its brand image is damaged. The decline of market share and popularity is related to the following reasons:

\subsection{Brand Awareness Is Weak, Not Paying Attention to Brand Marketing}

Brand awareness refers to the impression of brand in the memory of consumers. It shows the ability of consumers to identify brands in different situations, including brand recognition and brand recall. The stronger the brand awareness is, the more consumers think about the brand when they purchase products, and the more likely they are to finally buy the brand [7]. At the same time, brand awareness will also affect the formation and intensity of brand association and brand image. Brand not only represents the strength, products and services of enterprises, but also has the effect of brand premium. Brand marketing is a process in which the target customers form the cognition recognition recognition of the enterprise brand, products and services by using various marketing strategies. From a high level, brand marketing is to show the image, popularity and good reputation of enterprises to consumers or customers, so as to form the brand image of products or services in the minds of customers and consumers. Brand marketing needs brand promotion planning, capital investment, progress coordination and brand maintenance to maintain the vitality of the brand and increase the brand reputation and customer loyalty. College students have a wide range of knowledge, independent thinking and cognitive ability. When choosing the postgraduate entrance examination institution, the famous postgraduate entrance examination brand will directly attract some customers to choose this institution. The postgraduate entrance examination institutions did not pay attention to brand marketing, ignoring that brands and products need to be operated as well. Brand marketing needs to take the enterprise concept, education concept and so on into the hearts of customers, so that customers can understand the organization, corporate culture and why the organization is trustworthy. Brand marketing is not a simple marketing method, it needs to plan every step careful- 
ly. Brand marketing depends on product publicity and its connotation is higher than marketing advertising, and it needs management and protection.

\subsection{Blind Advertising Leads to Poor Brand Communication}

Brand communication refers to various direct and indirect methods for enterprises to inform consumers of brand information, persuade them to buy brands and maintain brand memory. Communication is the main way to build brand power. Brand communication is an effective way for enterprises to meet the needs of consumers and cultivate their loyalty [8]. In the service industry, the purpose of advertising communication is to make consumers have a certain willingness to buy, focusing on the dissemination of consumer awareness, stimulating a way of behavior and making it a habit of life, rather than promoting products. Therefore, advertising is not to directly promote their own products, but to promote the concept associated with their own leading products, so as to promote consumers to buy goods and services of this brand. In addition, blind advertising will also lead to brand equity crisis because the advertising costs are too large and the brand benefits cannot bear this huge expenditure. To advertise, we must have the strength to bear a large amount of advertising expenses.

As a service company, the old model of product marketing only leads to the low efficiency of advertising communication, the decline of popularity and the lack of brand features:

At the beginning of each semester, there will be a seminar for postgraduate entrance examination. Please invite well-known teachers to give lectures and send them to the postgraduate entrance examination institution to print the interpretation of postgraduate entrance examination policies and some materials. Famous teachers and materials will attract some people. But at the beginning of school, competitors will also hold lectures, resulting in clustering. Students' capture of information is fragmented, unable to have a clear evaluation and cognition of each institution.

Advertising is not equal to brand promotion. Brand has connotation. Putiangaidi pastes posters in the campus of colleges and universities. There are many posters in the posters, which are disorderly. The recognition of college students is very low, so they can't transmit information effectively.

School enterprise cooperation. One way is for the postgraduate entrance examination institutions to look for college students to be part-time student agents, to promote and recruit students on behalf of them; the other way is to sponsor some activities with student organizations, such as the student union and student associations, and carry out publicity during the activities, such as naming, distributing flyers, hanging propaganda banners at the activity venues, etc. After that, the conversion rate is very low, and people gradually get tired of these things, as well as memory fatigue. I just think these promotions are useless advertisements. I didn't have a deep understanding of the company and its products, and I just started to understand them again when I needed. 
It needs brand promotion planning, capital investment, progress coordination and brand maintenance to maintain the vitality of the brand and increase the brand reputation and customer loyalty. College students have a wide range of knowledge, independent thinking and cognitive ability. When choosing the postgraduate entrance examination institution, the famous postgraduate entrance examination brand will directly attract some customers to choose this institution. The postgraduate entrance examination institutions did not pay attention to brand marketing, ignoring that brands and products need to be operated as well. Brand marketing needs to take the enterprise concept, education concept and so on into the hearts of customers, so that customers can understand the organization, corporate culture and why the organization is trustworthy. Brand marketing is not a simple marketing method, it needs to plan every step carefully. Brand marketing depends on product publicity and its connotation is higher than marketing advertising, and it needs management and protection.

\subsection{Unreasonable Market Personnel System}

According to the principle of employee allocation: the principle of element usefulness, the principle of energy position correspondence, the principle of complementary value-added, the principle of dynamic adaptation, the principle of elastic redundancy [9]. Principle of element usefulness: everyone is useful, and work should be assigned according to their special abilities; principle of correspondence of ability and position: employees with different abilities should be assigned to different positions due to their different levels of competence; principle of complementary value-added: every inch is short, every inch has its own advantages, and individual ability is limited, so team members need to cooperate with each other; principle of flexibility and miscellaneous requires tasks and people to be assigned There is a gap between the abilities of employees, and employees should not be under too much pressure.

Marketing personnel plays an important role in the promotion of enterprise products. The performance of the company is closely related to the marketing personnel. At present, most of the market personnel system of the postgraduate entrance examination institutions is a university to arrange a marketing personnel and a course consultant. The marketing personnel of postgraduate entrance examination need more physical strength than mental power, and they need high performance. A marketing personnel is facing a large number of college students with 30,000 or so customers. The marketing personnel are weak and have no cooperation. No one can give advice in time, which violates the principle of functional correspondence, complementary value-added principle, dynamic adaptation principle and elastic redundancy principle in the principle of employee allocation [10]. In the long run, employees will be slack. The decrease of performance, the decrease of sales staff's sense of achievement, and the final turnover lead to the high mobility of market staff, and also bring huge direct and indirect costs to the enterprise. 


\subsection{Poor Customer Management, Poor Word-of-Mouth Marketing}

Customer Relationship Management (CRM) is a process [11] in which enterprises coordinate the sales, marketing and service interaction between enterprises and customers by using corresponding information technology and Internet technology to improve their management mode and provide customers with innovative and personalized customer interaction and service in order to improve their core competitiveness [12]. Its ultimate goal is to attract new customers, retain old customers and turn existing customers into loyal customers, and increase the market. Customer management requires that customers be the center, and enterprises provide satisfactory services for students, so that customers can finally obtain ideal results through good services. Students get ideal results, which naturally leaves a good reputation for the enterprise. For the growing brand, some consumers have a certain understanding of it, and some of them have a good impression on the brand. Word of mouth promotion can let consumers automatically spread the good evaluation of the company's products and services, let people understand the products through word of mouth, establish brand awareness, and finally achieve the purpose of selling products and providing services [13].

The customer management of postgraduate entrance examination institutions is poor and does not pay attention to word-of-mouth marketing. Every 50 or so students in the middle and high-end classes of the postgraduate entrance examination institution are equipped with a counselor and a teaching assistant, who is responsible for sending notices and dealing with student affairs; the teaching assistant is responsible for course answering. Even though the teachers and professors are very good, the students don't know how much they understand. There is no systematic management for the time, energy and ability of one-to-one multi-question answering by the TA, and how the examination results are, so the pass rate of the postgraduate entrance examination can't reach the ideal effect. The postgraduate entrance examination training service is a one-time consumption service. When the training class starts, the focus of the whole enterprise is transferred to the next batch of customers, so it is only to maintain normal in the old customer management, rather than to provide good services.

The life circle of college students is not big. The people around are some senior brothers and sisters who meet in the same class or through other ways. Therefore, the word-of-mouth transmission of students is very important for brand communication, but the postgraduate entrance examination institutions do not pay attention to the word-of-mouth transmission. There is little interaction between the ideal students and the next students, and there is little investment in the interaction between old customers and new customers.

\section{An Analysis of the Problems in the Brand Construction of the Postgraduate Entrance Examination Institutions}

From the above analysis of the problems and causes, it can be seen that the en- 
terprise brand has been initially constructed, but the brand awareness has a downward trend because it has not continued to invest in the cost of brand operation. Poor customer management, weak brand awareness, blind advertising, unreasonable market personnel system, resulting in poor brand communication, internal advantages not known by customers, and market share decline.

With consumers' emphasis on self and individual needs, the market is increasingly turning to diversification, personalization and subdivision, and China's consumer market has gradually moved from "commodity consumption" to "brand consumption". In the era of brand consumption, whether an enterprise can cultivate its own brand and create a strong brand will determine the competitiveness of a brand enterprise in the market [14].

The cultivation and shaping of brand need two aspects of operation. In terms of connotation, the postgraduate entrance examination institutions have strong teachers, perfect curriculum system and numerous teaching points, which play a huge advantage in brand building and need to be maintained. In the extension operation, there is no perfect brand maintenance plan. Especially in marketing, we do not pay attention to brand awareness publicity, and the awareness of brand promotion management and maintenance is even weaker.

\subsection{Innovation of Brand Construction in Postgraduate Entrance Examination}

Brand building is the behavior and effort of brand owner to plan, design, publicize and manage the brand [15]. The construction of enterprise brand should be based on honesty and credit, with product quality and product characteristics as the core. Only in this way can consumers' credit recognition be cultivated, and the products of enterprises have market share and economic benefits. Brand strategy is a theory about how to get better performance in market enterprises. To establish brand strategy awareness is to realize the great benefits that brand can bring to enterprises and recognize the importance of brand construction. Therefore, a series of measures are taken to continuously innovate and make brand more vital.

The brand maintenance of postgraduate entrance examination institutions needs to formulate new brand strategy. There is a sharp contrast between the popularity of postgraduate entrance examination and the difficulty of postgraduate entrance examination. Therefore, the training institutions of postgraduate entrance examination should start from the perspective of users and establish a new brand strategy centered on solving customer problems, with the goal of solving the problem. How to solve the difficult problem of postgraduate entrance examination needs to be based on a high position, grasp the pain point of users, do a lot of research on college students, use new technology to obtain a large number of data information, use Porter five force model to analyze and evaluate, and work out the brand strategy of solutions. At the same time, the formulation of brand strategy should be based on innovation. The 21 st century is an era of information explosion and intelligence. The innovation way of brand should be 
combined with new media, combined with app, make use of technological advantages to penetrate customers, and then expand brand awareness.

\subsection{Innovation of Talent Training Mode in Enterprises - Improving the Staff Training System}

Enterprise staff training, as a basic way and excellent way to directly improve the ability level and skills of business managers, provide enterprises with new working ideas, knowledge, information and skills, increase the talents and professionalism of employees, and innovate [16], is the most important development of human resources and more important investment of human capital than material capital investment. The most difficult thing to change in the world is people. Talent is an important resource for enterprise development. Human change is a gradual process. At present, we are in an era of change. The knowledge reserve, marketing skills and communication skills of sales personnel are important factors that determine the success of sales. Therefore, the organization needs to carry out all-round training on personal experience, communication and business ability. In order to understand the campus market of college students as the training principle, design the training plan around what is the campus market, the characteristics of the campus market and how to do a good job in the campus market, invite the experienced trainers of the campus market to give lectures, combine the methods of scenario analysis, simulation sales and case sharing, formulate performance indicators during the training period, carry out actual combat in the training, and put the training into practice, make a long-term series of courses.

More than half of university graduates want to go to graduate school. The number of graduate students is increasing year by year, and the pressure of postgraduate entrance examination is also increasing rapidly. Marketing specialists are faced with college students, who are an active group with a wide range of contacts. Enterprises should start from customer demand and stimulate potential demand. First of all, we should publicize the importance of postgraduate entrance examination, so that more customers will have the intention of postgraduate entrance examination. Second, we should let customers form a shortcut thinking of postgraduate entrance examination, and then let customers choose postgraduate entrance examination institutions. These two concepts need to be completed by market specialists, who need to deeply explore the needs of college students and understand the daily life, interests and values of customers. Therefore, enterprise employees should learn marketing theory, accept marketing skills training, and also need to learn psychological knowledge, so as to clearly know customer needs and provide services required by customers.

\subsection{Innovation of Marketing Mode-Strengthen Online Marketing}

Internet is a powerful marketing tool, which has many functions such as channel, promotion, electronic transaction, interactive customer service, market information analysis, etc. [17]. Online marketing has the following advantages: 
accurate target users, can master detailed user information, can reach the target users to the greatest extent effectively; huge user group, browsing volume and viscosity; strong word-of-mouth marketing, fast communication speed and high efficiency. The social circle based on the relationship between friends and classmates can form a huge place for word-of-mouth marketing. With the rapid spread of news, the marketing effect can be achieved more easily.

Wechat is the most popular Internet marketing medium for college students. Wechat allows people to communicate privately, keep in touch, understand each other and increase trust. The research institutes should vigorously develop online marketing in the existing offline marketing mode. Give full play to the advantages of Internet + and use new media platform for marketing. At present, the wechat platform of the postgraduate entrance examination organization only has the daily work of pushing. A wechat marketing team should be specially established to increase the number of College Students' fans, innovate the content of pushing, increase the interaction with fans, and make full use of the wechat platform instead of staying on the most basic functions. The popularity of smart phones makes college students spend more time on mobile phones every day. The drawback of offline promotion is that advertising can't let people understand a brand and its concept culture in depth, and online can make up for these deficiencies. Enterprises can make interesting video animation or copywriting, and at the same time, with the help of the newly developed infocom and other software of the postgraduate entrance examination institution, they can set up the mode of watching and sharing the red packets, so that customers can have a deep understanding of the postgraduate entrance examination, the postgraduate entrance examination brand, education concept, etc., and then increase the recognition of the brand.

\subsection{Product Innovation-Launch Boarding Postgraduate Entrance Examination Based on Customer Experience}

Product innovation is to improve or create products, further meet customer needs or open up new markets. Product innovation originates from the market demand and the product technology demand of the market for the enterprise. That is to say, the technology innovation activities take the market demand as the starting point, define the research direction of product technology, and create marketable products suitable for this demand through the technology innovation activities, so that the market needs to be satisfied. In the buyer's market, customers play a leading role, and the competition mainly develops among service providers. The internal motive force of pursuing profits and the external pressure of competition force enterprises to respect customers and improve services. At the same time, the customer is the real evaluator of service brand. Only when the customer is satisfied can the brand truly become a brand. This requires starting from the customer's point of view and considering issues, in the development of appropriate service standards strictly implemented on the basis of service product innovation to make customers happy. 
For graduate students, learning environment is an extremely important thing. Customers are willing to pay a large cost to obtain a good user experience. In the places where postgraduates study, the library needs to line up to occupy seats, while the classroom has no fixed special classroom for postgraduates. And people come and go, the environment is noisy, it is easy to be disturbed by the surrounding people, which leads to the lack of concentration in learning. Therefore, in order to pursue customer satisfaction, we launched the boarding postgraduate entrance examination, concentrated customers in a closed learning environment, simulated the high school life and learning style. Customers work and rest in the same way every day, can make the most of their time, and have the convenience of mutual supervision and learning. Learning efficiency improves the success rate of postgraduate entrance examination.

\subsection{Customer Positioning Innovation}

Marketing customers are transferred from junior students to freshmen and sophomores to tap potential customers.

Due to the limitation of their own strength, modern enterprises cannot provide the market with products and services that can meet all needs. In order to compete effectively, enterprises must subdivide the market, choose the most profitable target market, concentrate the resources of enterprises, and formulate effective competitive strategies to gain and increase competitive advantage. After market segmentation, the sub market is more specific, and it is easier to understand the needs of consumers. Enterprises can determine their own service objects, i.e. target market, according to their own business ideas, policies, production technology and marketing forces. Market segmentation is conducive to the research of potential demand, the development of new markets, and the improvement of market share [18]. It can understand the needs and purchasing potential of various consumer groups, so as to find new market opportunities. Market positioning determines the direction of advertising and the target of brand communication. If the market positioning is not accurate, it will increase the cost of capital and manpower, reduce the efficiency and produce the opposite result. Before marketing, we must conduct research and determine the publicity objectives. With accurate target market positioning and effective publicity methods, the brand image will gradually be established in the customer group.

The focus of brand promotion is shifted and integrated, and the customer orientation is changed from junior students to freshmen, sophomores and juniors. The target of marketing is junior college students. However, junior students have no clear consideration on whether to apply for postgraduate entrance examination or not. It is easy to make a wrong decision on impulse consumption due to the lack of information about the training class. As a freshman, college students are in a confused period, full of curiosity about the future. At this time, the postgraduate entrance examination institutions can provide low-cost or even free services for college students' needs, such as CET-4 and CET-6, computer 
test, Putonghua test and other basic and necessary tests. It can make college students understand the enterprise deeply, know its strength, and have a sense of trust; meanwhile, it reflects the humanistic care of the enterprise, improves the popularity of the enterprise, and increases customer loyalty.

\subsection{Service Innovation-Introduction of 5-Person Group Teaching Assistants}

One of the principles of service marketing strategy is the principle of service quality management. Service is the foundation of service marketing, and service quality is the core of service marketing. The quality of service is the magic weapon for enterprises to win in the competition, no matter in the tangible products or in the service industry. In service marketing, service provision and consumption are carried out simultaneously. Enterprises should pay attention to the management of service quality, so that the service level can meet the needs of customers. The postgraduate entrance examination institutions need to continuously improve the service quality.

The service process of the postgraduate entrance examination institution is from enrollment, class to examination. Under the condition that the teachers and curriculum system are dominant, improving customer satisfaction needs to ensure the passing rate of the postgraduate entrance examination. The process of postgraduate entrance examination is painful and lonely. On the one hand, the pain comes from the study pressure and competition pressure, on the other hand, it comes from the influence of the surrounding people, such as those who escort graduate students, find good jobs, and get admission notices from foreign universities. In the process of postgraduate entrance examination, students need not only a tutor and supervisor, but also a person who supports and accompanies them in spirit, and the graduate students who are willing to do part-time job just meet this demand. Graduate students are the role model and spiritual pillar of students. At the same time, they are familiar with the curriculum system and can provide guidance in both learning and life. The cost of part-time postgraduates is low. Enterprises use less cost to ensure the passing rate of students, to ensure customer satisfaction, through word-of-mouth transmission, it has a good marketing effect. At the same time, it improves the brand awareness and the brand trust.

\subsection{Precision Marketing}

Precision marketing is based on the precise positioning, relying on modern information technology means to establish a personalized customer communication service system, and realize the measurable low-cost expansion of the enterprise. It is one of the core viewpoints of the network marketing concept with attitude. Precision marketing first needs to find the target customers, and then with the help of the developed communication system in the 21 st century, it can achieve direct contact and communication with customers, maintain a good relationship with customers, and finally obtain customers. Now social media has 
powerful functions. Using social media to get customers' information is convenient, low-cost, and can directly and effectively transfer information to customers. After obtaining information from the online, the trust is increased and the sales are more convenient through the offline face-to-face communication.

According to the characteristics of college students, this kind of precise marketing scheme can be implemented for the clients of postgraduate entrance examination institutions: the first step is to collect the detailed information. There are several colleges, classes in each college, who are in each class, which dormitories they live in, and the second step is to set up a student agent in each class to file the students in each class According to the number of people in each class, set performance indicators for marketing personnel in each class. At night, regularly arrange college students to act as part-time agents to conduct one-to-one visit and publicity to the dormitories of this class, record the customer information registration, who has the willingness to take the postgraduate entrance examination, who has the willingness to report to the postgraduate entrance examination class, and who is willing to report to the postgraduate examination class, all of which need to be recorded and tracked at all times. Online publicity: unified by the company edit the copy design poster, arrange each class agent to forward online social circle, each class agent needs to ensure that all students in the class can see the social circle information, and ensure the effective transmission of information.

\section{Conclusions}

The purpose of this paper is to study the problems, causes and countermeasures in the construction of the educational brand of the postgraduate entrance examination institutions. By consulting the relevant literature of the construction of the educational brand and interviewing the staff of the postgraduate entrance examination institutions, this paper analyzes the current situation of the market of the postgraduate entrance examination institutions, and puts forward the existing problems and solutions for the current development of the construction of the postgraduate entrance examination institutions' brand.

The popularity of brand reflects the value of an enterprise. At present, the postgraduate entrance examination institution is in the growth period of scallop brand life cycle theory. It has certain popularity and needs to carry out brand maintenance management. The purpose is to be stable in the mature period and get more profits in a mature period.

Corporate brand is the cohesion of corporate culture and the guidance of values. If the enterprise brand wants to follow the theory of scallop life cycle, it needs brand management. Brand management needs investment and innovation. Innovation is not only the development demand of the time, but also the vitality of enterprise brand construction and maintenance. Brand innovation should be combined with the characteristics of the times, with the help of the power of science and technology, tap the needs of customers, find a good way to 
realize the brand leap again. The research institutes do well in teachers, research and development, hardware facilities, and need to increase innovation and investment in brand marketing. This paper puts forward the following solutions: brand building innovation of postgraduate entrance examination, enterprise talent training mode innovation-improving employee training system, product innovation-launching boarding postgraduate examination based on customer experience, customer positioning innovation, service innovation-introducing 5-person group teaching assistants.

\section{Conflicts of Interest}

The authors declare no conflicts of interest regarding the publication of this paper.

\section{References}

[1] Tian, L. and Zhang, L. (2004) Research on Customer Relationship Management Based on Value Theory and Data Mining. School of Management, Jinan University, Jinan.

[2] Mei, J.W. (2005) On Brand Building. Journal of Jiangsu Vocational and Trade College, No. 2, 46-49.

[3] Chen, Y. (2013) Brand Maintenance and Development of Education and Training Based on the Concept of Life Cycle. Journal of Ningbo University (Education Science Edition), 35, 103-105.

[4] Ge, X.F. (2014) Problems and Development Strategies in Brand Building of Enterprises. Market Modernization, 28, 137-138.

[5] Yang, Y. (2001) Coca Cola Beijing Olympic Marketing Analysis. Zhengzhou University, Zhengzhou.

[6] Fang, C.J. (2016) Brand Communication of Farmer Cooperatives: A Multi Case Study Based on 10 Farmer Cooperatives in Beijing, Zhejiang and Fujian. China Farmer Cooperatives, No. 5, 50-52.

[7] Qin, P. (2018) A Study on the Book Advertisement of the Declaration in the Early 20th Century (1901-1911). Zhejiang University of Industry and Commerce, Hangzhou.

[8] Liao, J. (2018) Sales Strategy Analysis of Chinese Brand of X Coffee Company. Southwest Jiaotong University, Chengdu.

[9] Zhao, F.H. (2011) Research on Incremental Talent Management System of Petroleum Enterprises. China University of Petroleum (East China), Beijing?.

[10] Tang, H.Q. (2007) Research on Human Resource Planning of BF Planning Institute. Tianjin University, Tianjin.

[11] Gu, Y. (2019) Research on Marketing Strategy of Private Banking Business of Inner Mongolia Branch of Bank A. Inner Mongolia University of Finance and Economics, Hohhot.

[12] Xu, G.S. (2016) Research on the Construction of Practical Training Materials for Business English Major in Higher Vocational Education Based on Work Process. Science and Technology Horizon, No. 12, 174+192.

[13] Cai, X.J. (2017) Research on Brand Marketing Strategy of W Trusteeship Education Chain Organization. Huaqiao University, QQuanzhou!? 
[14] Zhang, S.H. (2011) On Brand Planning, Management and Operation of Enterprises. Journal of Jiangsu Normal University of Technology, 17, 5-8.

[15] Jiao, J.J. (2018) Brand Building Research of ZS Company. Beijing Jiaotong University, Beijing.

[16] Li, X.C. (2015) Research on Employee Training Management of Puguang Branch of Zhongyuan Oilfield. China University of Petroleum (East China), Qingdao.

[17] Sun, W.Y. (2012) Research on Marketing Strategy of Online Original Women's Wear Brand: A Case Study Based on "OSHA” Women's Wear Brand. Xiamen University, Xiamen.

[18] Yao, Y. (2017) Research on Marketing Strategy of Community Banking Business of Bank. Nanjing Normal University, Nanjing. 